University of Nebraska - Lincoln

DigitalCommons@University of Nebraska - Lincoln

Back-face strain compliance relation for compact specimens for wide range in crack lengths

J. C. Newman Jr.

Mississippi State University, j.c.newman.jr@ae.msstate.edu

Y. Yamada

NASA Glenn Research Center

M.A. James

Alcoa Technical Center

Follow this and additional works at: https://digitalcommons.unl.edu/nasapub

Part of the Physical Sciences and Mathematics Commons

Newman, J. C. Jr.; Yamada, Y.; and James, M.A., "Back-face strain compliance relation for compact specimens for wide range in crack lengths" (2011). NASA Publications. 72.

https://digitalcommons.unl.edu/nasapub/72

This Article is brought to you for free and open access by the National Aeronautics and Space Administration at DigitalCommons@University of Nebraska - Lincoln. It has been accepted for inclusion in NASA Publications by an authorized administrator of DigitalCommons@University of Nebraska - Lincoln. 


\title{
Back-face strain compliance relation for compact specimens for wide range in crack lengths
}

\author{
J.C. Newman Jr. ${ }^{a, *}$, Y. Yamada ${ }^{b}$, M.A. James ${ }^{c}$ \\ a Department of Aerospace Engineering, Mississippi State University, MS 39762, United States \\ ${ }^{\mathrm{b}}$ Ohio Aerospace Institute, NASA Glenn Research Center, Cleveland, $\mathrm{OH} 44135$, United States

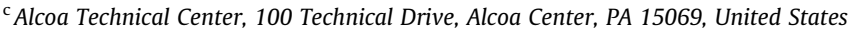

\section{A R T I C L E I N F O}

\section{Article history:}

Received 23 June 2011

Accepted 8 July 2011

\section{Keywords:}

Cracks

Compact

Back-face strain

Elasticity

\begin{abstract}
A B S T R A C T
A back-face strain (BFS) compliance relation has been developed for the standard compact $\mathrm{C}(\mathrm{T})$ specimen for a very wide range in crack-length-to-width $(a / W)$ ratios. Both finiteelement and boundary-element methods were used to develop the BFS relation for $a / W$ ratios from 0.2 to 0.95 . In addition, experimentally determined compliance values on four metallic materials compared well with the new relation over nearly the complete $a / W$ range. The new relation can be used to monitor crack-length-against-cycles using computerized crack-monitoring systems that are currently used with the crack-mouthopening-displacement (CMOD) gage method, and the relation has been cast in a standard form compatible with existing compliance crack length monitoring systems.
\end{abstract}

(c) 2011 Elsevier Ltd. All rights reserved.

\section{Introduction}

Compact $\mathrm{C}(\mathrm{T})$ specimens are the most widely used test specimens to measure fatigue-crack-growth rates in metallic materials. Two methods have been used to automatically monitor crack length in these specimens as a function of compliance. They are the crack-mouth-opening-displacement (CMOD) gage and the back-face strain (BFS) gage, as shown in Fig. 1. A CMOD relationship ( $a / W$ against EVB/P, where $E$ is elastic modulus, $V$ is CMOD, $B$ is thickness and $\mathrm{P}$ is applied load) is standardized in ASTM E 647 [1], the fatigue-crack-growth standard, but the BFS relation has not yet been included.

Some 30 years ago, efforts were made to develop a BFS relation for the standard compact specimen, as proposed by Dean and Richard [2]. The resulting negative elastic strain per unit load, calculated on the back-face of the $C(T)$ specimen using a two-dimensional finite-element method was correlated with the crack-length-to-width ( $a / W)$ ratio, as shown in Fig. 2. Later, Maxwell [3] also used the finite-element method to determine back-face strain values for $a / W$ ratios from 0.2 to 0.8 and developed an expression relating crack length and back-face strain (dashed curve in Fig. 2). Shaw and Zhao [4] also determined some additional experimental results on 2024-T351 aluminum alloy, and these results are shown by the diamond symbols in Fig. 2.

More recently, some additional BFS crack-length relations have been developed for the C(T) specimen. Riddell and Piascik [5] used FRANC2D [6,7] (finite-element code) and developed a relation shown by the solid curve in Fig. 2. Although not stated, the range of validity of the equation was most likely $0.1 \leqslant a / W \leqslant 0.9$, since this was the range of their analyses. However, the "log" functional form of the BFS compliance equation used by Riddell and Piascik was not well suited for use in crackmonitoring systems (such as Ref. [8]) without additional programming to implement the log form.

Later, Newman and Johnston [9], NASA Langley Research Center, refit the Riddell-Piascik FRANC2D results (solid symbols in Fig. 2) using the same form as the CMOD equation (EVB/P) used in the ASTM E 647 standard [1] (absolute strain times

\footnotetext{
* Corresponding author. Tel.: +1 6623251521.

E-mail address: j.c.newman.jr@ae.msstate.edu (J.C. Newman).
} 


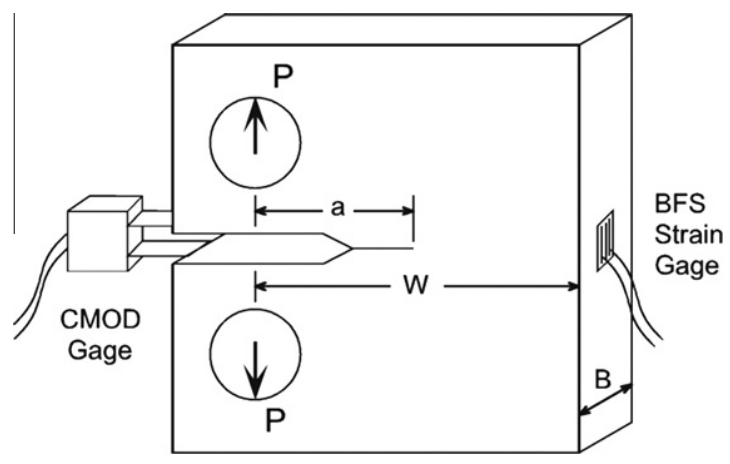

Fig. 1. Compact specimen with CMOD and BFS gages.

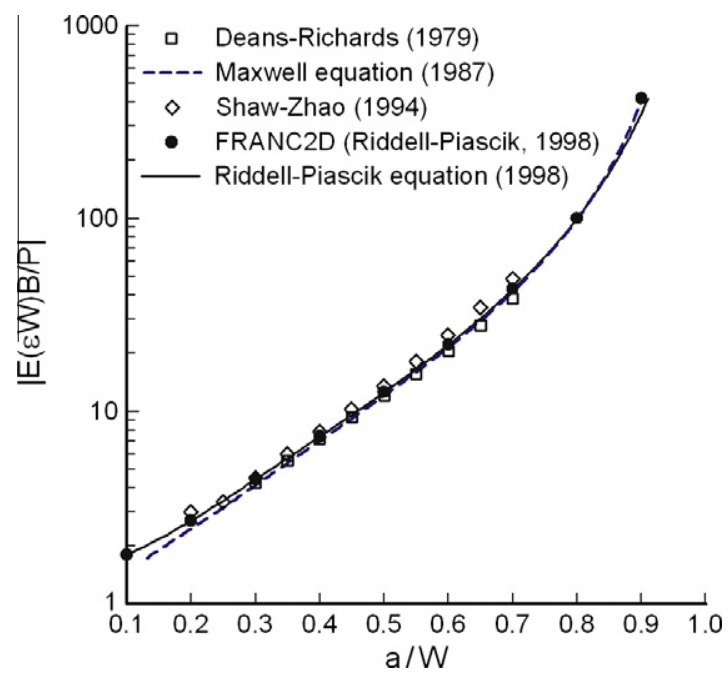

Fig. 2. Normalized back-face strain results from the literature for compact specimens.

width replaces displacement as $|E(\varepsilon W) B / P|)$. This standard form enabled the use of commonly used crack-length monitoring systems by simply inputting new coefficients (note that the compressive strain measured at the back-face necessitated changing the strain-gage polarity). The Newman-Johnston equation was only valid for $a / W=0.2-0.8$ and is

$$
a / W=A_{0}+A_{1} U+A_{2} U^{2}+A_{3} U^{3}+A_{4} U^{4}+A_{5} U^{5}
$$

where $U=1 /(\sqrt{ } \mathrm{A}+1)$ and $A=|E(\varepsilon W) B / P|$. The coefficients for $0.2<a / W<0.8$ are:

$$
\begin{array}{lrl}
A_{0}=1.0343 & A_{1}=-2.8098 & A_{2}=4.1335 \\
A_{3}=-23.694 & A_{4}=76.371 & A_{5}=-83.25
\end{array}
$$

In experiments, the Newman-Johnston BFS expression worked very well for $a / W$ ratios less than 0.8 . However, discrepancies between actual and calculated crack lengths for $a / W$ ratios greater than about 0.8 were observed. The purpose of this technical note is to understand the differences in the various BFS expressions and to develop an expression for a wide range in crack-length-to-width ratios $(0.2<a / W<0.95)$ using the standard ASTM compliance form.

\section{Analyses}

Herein, two analyses have been conducted: (1) FRANC2DL and (2) FADD2D to determine the relation between crack length and the back-face strain on the standard C(T) specimen. FRANC2DL [10,11] (finite-element code) was used to determine the normalized back-face strain results for some very deep cracks. The FADD2D [12], boundary-element code, was used to analyze the $C(T)$ specimen over a wide range of crack-length-to-width $(a / W)$ ratios $(0.1-0.95)$. In the analyses, two methods were used to determine the strain value as a function of $a / W$ ratios. First, the compressive normal stress, $\sigma_{\mathrm{yy}}$, along the centerline at the back-face was calculated and the corresponding strain was calculated by dividing the normal stress by the 
Table 1

FADD2D and FRANC2DL normalized back-face strain results.

\begin{tabular}{|c|c|c|c|c|}
\hline $\mathrm{a} / \mathrm{W}$ & $\begin{array}{l}\text { FADD2D } \\
|\mathrm{E}(\varepsilon W) \mathrm{B} / \mathrm{P}|\end{array}$ & $\mathrm{a} / \mathrm{W}$ & $\begin{array}{l}\text { FADD2D } \\
|\mathrm{E}(\varepsilon W) \mathrm{B} / \mathrm{P}|\end{array}$ & $\begin{array}{l}\text { FRANC2DL } \\
|\mathrm{E}(\varepsilon W) \mathrm{B} / \mathrm{P}|\end{array}$ \\
\hline 0.10 & 1.783 & 0.60 & 22.35 & 22.31 \\
\hline 0.15 & 2.162 & 0.65 & 30.74 & - \\
\hline 0.20 & 2.704 & 0.70 & 43.83 & 43.77 \\
\hline 0.25 & 3.449 & 0.75 & 65.93 & - \\
\hline 0.30 & 4.443 & 0.80 & 107.3 & 107.2 \\
\hline 0.35 & 5.742 & 0.85 & 198.0 & 197.9 \\
\hline 0.40 & 7.437 & 0.90 & 460.1 & 462.7 \\
\hline 0.45 & 9.660 & 0.93 & 937 & - \\
\hline 0.50 & 12.62 & 0.95 & 1809 & - \\
\hline 0.55 & 16.66 & - & - & - \\
\hline
\end{tabular}

modulus of elasticity $(E)$. This is referred to as the point value (gage length $g=0$ ). In the second method, the strain was calculated from displacements measured across the centerline at a gage length $g / W=0.04(g=3.2 \mathrm{~mm}$ and $W=76 \mathrm{~mm})$. These latter results are given in Table 1. Using the FADD2D and FRANC2DL results, an improved wide-range equation was developed and is given by

$$
\begin{aligned}
& a / W=A_{0}+A_{1} U+A_{2} U^{2}+A_{3} U^{3}+A_{4} U^{4}+A_{5} U^{5} \\
& A_{0}=1.0033 \quad A_{1}=-2.35 \quad A_{2}=1.3694 \\
& A_{3}=-15.294 \quad A_{4}=63.182 \quad A_{5}=-74.42
\end{aligned}
$$

where $U=1 /(\sqrt{ } A+1)$ and $A=|E(\varepsilon W) B / P|$ for $0.2<a / W<0.95$. Note that Eq. (2) is the same as Eq. (1), but with new coefficients that applies over a wider $a / W$ range.

Fig. 3 shows the percent difference in calculated $a / W$ values using the present equation (Eq. (2)) and the FADD2D results as a function of $a / W$. Here two back-face strain conditions were used: (1) a standard strain-gage size $(g=3.2 \mathrm{~mm}$, height of active strain-gage section on a $W=76 \mathrm{~mm}$ specimen) and (2) a point value $(g=0)$. The strain-gage size is commonly used in fatigue-crack-growth rate tests. The agreement between the equation and the analysis results for the normal strain-gage size were within $\pm 0.05 \%$ over the full range of claimed validity. Using a larger-height strain gage size would have resulted in larger differences for very deep cracks $(a / W>0.8)$.

The normalized compliance in terms of crack length is given by

$$
|E(\epsilon W) B / P|=\left(1.41-1.462 \alpha+20.45 \alpha^{2}-26.83 \alpha^{3}+11.45 \alpha^{4}\right) /(1-\alpha)^{2}
$$

where $\alpha=a / W$ for $0.2 \leqslant a / W \leqslant 0.95$.

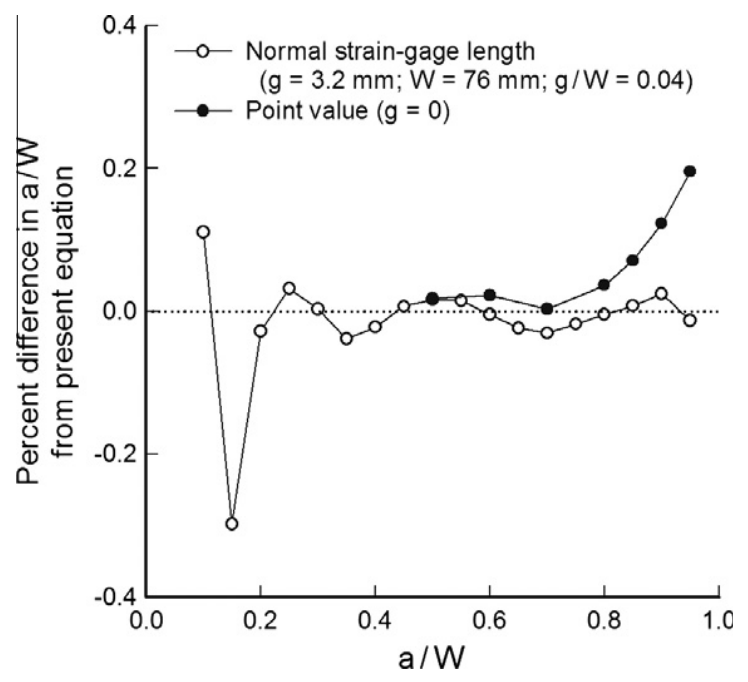

Fig. 3. Percent difference in crack-length determination from present equation for a normal strain-gage size or a point value of strain. 


\section{Results and discussion}

Fig. 4 shows a comparison among the more recent BFS analysis results and corresponding equations. The solid curve shows the Riddell-Piascik equation [5]; and the Newman-Johnston equation (Eq. (1)) is shown as the small-dashed curve. The results in Fig. 4 show that the Riddell-Piascik equation applies for $a / W$ ratios from 0.2 to 0.9 , while the NewmanJohnston equation can only be applied up to $a / W$ ratios of 0.8 . Note that both of these equations are plotted beyond their range of validity ( $a / W=0.9$ and 0.8 , respectively). The previous FRANC2D results [5] and the current FRANC2DL and FADD2D results are shown as symbols. All of the analysis results were in very good agreement. The medium-dashed curve shows the new BFS equation (Eq. (2)), which was fit to the FADD2D and FRANC2DL results. The present equation is valid over a very wide range in $a / W(0.2-0.95)$.

Fig. 5 shows the percent difference in calculated $a / W$ values relative to the Newman-Johnston equation using either the various analyses or the equations as a function of $a / W$. These results show that the Riddell-Piascik equation is within $2 \%$ for $a / W$ ratios less than 0.9 ; and also shows that the Newman-Johnston equation is within $1 \%$ for $0.2 \leqslant a / W \leqslant 0.8$; and within $2 \%$ for $a / W<0.9$. The results from FRANC2DL and FADD2D analyses (open symbols) agreed well for deep cracks $(0.6 \leqslant a /$ $W \leqslant 0.9$ ). The coefficients in the Newman-Johnston equation were reevaluated by fitting to the FRANC2DL and FADD2D results from $a / W$ ratios from 0.2 to 0.95 . At $a / W=0.8$, a $1 \%$ difference in the crack-length determination would result in about

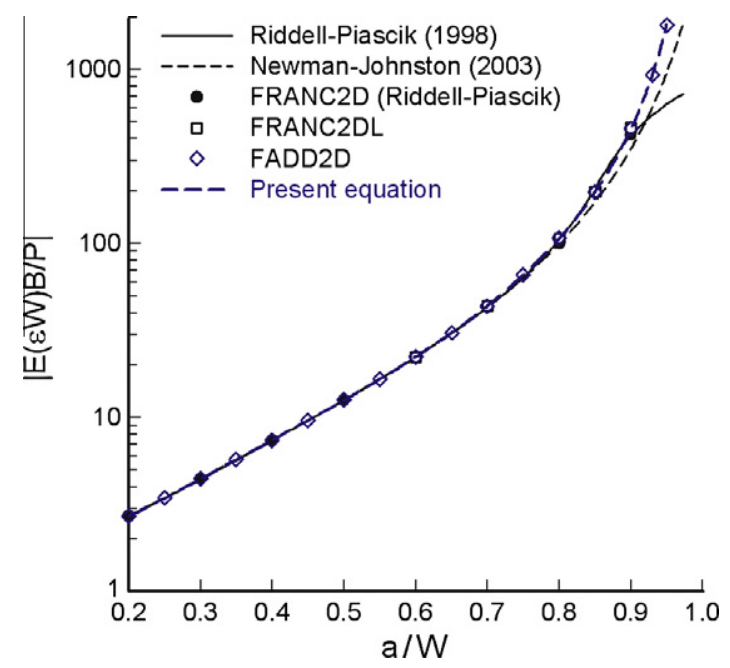

Fig. 4. Normalized back-face strain against crack length for compact specimens.

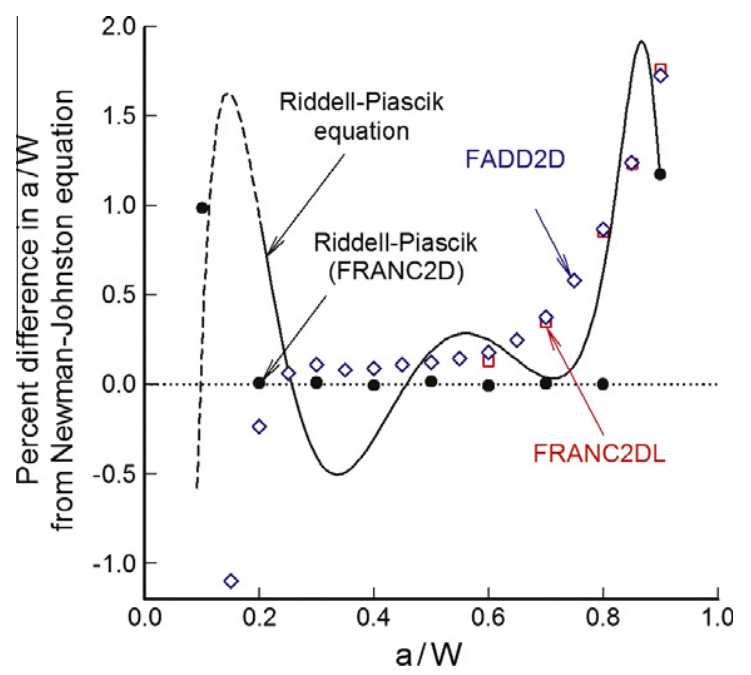

Fig. 5. Percent difference in crack-length determination from Newman-Johnston equation. 


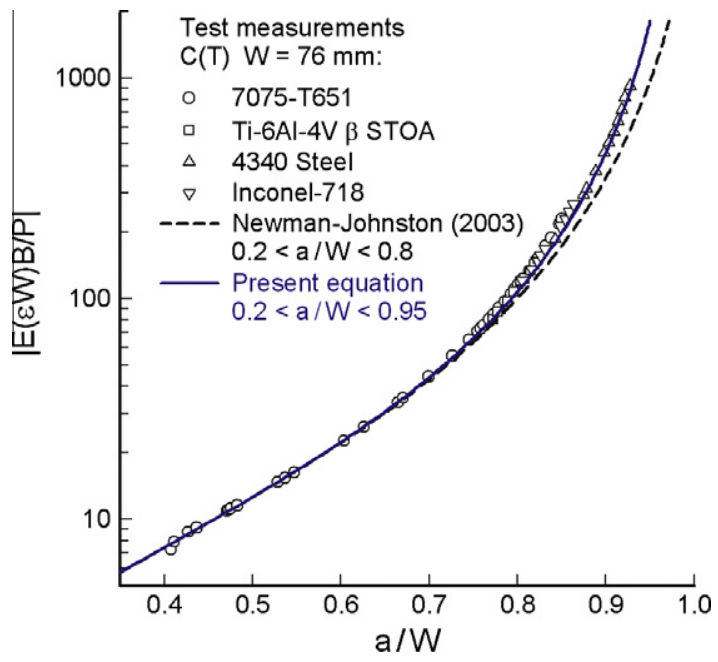

Fig. 6. Comparison of measured and calculated normalized back-face strain compliance against crack-length-to-width ( $a / W$ ) ratio.

an $8 \%$ difference in the stress-intensity factors, while at $a / W=0.9$, a $2 \%$ difference in crack-length determination would cause a $25 \%$ difference in the stress-intensity factors.

A BFS-gage compliance system [8] was used in fatigue-crack-growth-rate tests to monitor crack lengths. The original crack-length-monitoring system was set up to operate with a CMOD gage, but using the BFS-gage and current compliance form, only the coefficients in the compliance equation (same form as CMOD expression) and the strain-gage polarity had to be updated. During tests on four materials for very deep cracks, experimental strain-gage compliance values were found to differ from the Newman-Johnston equation, but they compare well with the improved wide-range equation, as shown in Fig. 6. Here the measured crack-length-to-width $(a / W)$ ratio on the surface of the specimen is compared with the computed compliance $|E(\varepsilon W) B / P|$. Some slight discrepancies occurred in the range of $a / W$ from 0.75 to 0.9 , which may have been caused by crack tunneling. The 7075-T651 and 4340 steel C(T) specimens exhibited very flat cracks and the cracks in the 4340 steel specimens were grown to very deep $a / W$ ratios, as shown by the triangular symbols. The Inconel-718 specimens also had fairly flat cracks, but the titanium alloy (Ti-6Al-4V $\beta$-STOA) had very rough, non-straight and meandering cracks. None the less, the agreement between the measured and calculated crack-length-to-width ratios from back-face strains was very satisfactory.

\section{Concluding remarks}

A back-face strain (BFS) compliance relation has been developed for the standard compact $\mathrm{C}(\mathrm{T})$ specimen for a very wide range in crack-length-to-width $(a / W)$ ratios. Both finite-element and boundary-element methods were used to develop the BFS relation for $a / W$ ratios from 0.2 to 0.95 . In addition, experimentally determined compliance values determined on fatigue-crack-growth tests on four materials (7075-T651, Ti-6Al-4V $\beta$ STOA, 4340 steel and Inconel-718) compared well with the new relation over nearly the complete $a / W$ range. The new relation can be used to monitor crack-length-against-cycles $(a, N)$ using computerized crack-monitoring systems over a very wide range in crack-length-to-width ( $a / W$ ) ratios.

\section{References}

[1] Standard Test Method for Measurement of Fatigue Crack Growth Rates. ASTM International E647, vol. 03.01; 2008.

[2] Dean WF, Richard CE. A simple and sensitive method of monitoring crack and load in compact fracture mechanics specimens using strain gages. J Test Eval 1979;7(3):147-54.

[3] Maxwell DC. Strain based compliance method for determining crack length for a C(T) specimen. AFWAL-TR-87-4046; 1987.

[4] Shaw WJD, Zhao W. Back face strain calibration for crack length measurements. J Test Eval 1994;22(6):512-6.

[5] Riddell WT, Piascik RS. A back face strain compliance expression for the compact tension specimen. NASA TM-208453; October 1998.

[6] Wawrzynek PA, Ingraffea AR. Interactive finite element analysis of fracture processes: an integrated approach. Theor Appl Fract Mech 1987;8:137-50.

[7] Wawrzynek PA, Ingraffea AR. FRANC2D: a two-dimensional crack propagation simulator. NASA CR-4572; March 1994.

[8] Donald K. Automated fatigue crack growth analysis - series 2001. User's reference manual. Version 3.03.02. Fracture Technology Associates. LLC; February 2003.

[9] Private Communication with Dr. John A. Newman, Will Johnston. NASA Langley Research Center, Hampton, VA; 2003.

[10] Gondhalekar S. Development of a software tool for crack propagation analysis in two-dimensional layered structures. MS Thesis. Kansas State University; 1992.

[11] James MA, Swenson DV. A software framework for two dimensional mixed mode-I/II elastic-plastic fracture. ASTM STP-1359. Philadelphia (PA): American Society for Testing and Materials; 1999. p. 111-26.

[12] Chang CC, Mear ME. A boundary element method for two-dimensional linear elastic fracture analysis. Int J Fract 1996;74:219-51. 